\title{
HABERMAS Y EL ROL DE LA RELIGIÓN EN LA ESFERA PÚBLICA: EL CASO DE LAS INTERVENCIONES CIUDADANAS EN LA SENTENCIA C-355-06*
}

\section{HABERMAS AND THE ROLE OF RELIGION IN THE PUBLIC SPHERE: THE CASE OF CITIZEN INTERVENTIONS IN SENTENCE C-355-06}

\author{
Javier Aguirre-Román** \\ Alonso Silva-Rojas*** \\ Ana Patricia Pabón-Mantilla ${ }^{* * * *}$ \\ Fecha de recepción: 27 de noviembre de 2015 \\ Fecha de aceptación: 29 de julio de 2016 \\ Disponible en linea: 30 de noviembre de 2016
}

\section{Para citar este artículo/To cite this article}

\begin{abstract}
Aguirre-Román, Javier; Silva-Rojas, Alonso \& Pabón-Mantilla, Ana Patricia, Habermas y el rol de la religión en la esfera pública: el caso de las intervenciones ciudadanas en la Sentencia C-355-06, 133 Vniversitas, 23-58 (2016). http://dx.doi.org/10.11144/Javeriana.vj133.hrre

doi:10.11144/Javeriana.vj133.hrre
\end{abstract}

Artículo resultado del proyecto de investigación Análisis de la propuesta de Jürgen Habermas acerca del rol de la religión en la esfera pública. Tres casos de la jurisprudencia de la Corte Constitucional de Colombia, grupo de investigación Politeia, Escuela de Filosofía, Universidad Industrial de Santander, financiado por la Vicerrectoría de Investigación y Extensión. Código: 1376.

** Doctor y magíster en filosofía, State University of New York, SUNY. Profesor asociado de la escuela de filosofía, Universidad Industrial de Santander, UIS. Miembro del grupo de investigación Politeia. Contacto: jaguirre@uis.edu.co

*** Doctor en ciencias políticas y magíster en filosofía, Universidad de Tubinga, Alemania. Profesor titular, Universidad Industrial de Santander, UIS. Director del grupo de investigación Politeia.Contacto: asilva@uis.edu.co

${ }^{* * * *}$ Doctora en derecho, magíster en hermenéutica jurídica y derecho. Profesora asociada, Facultad de Derecho, Universidad Autónoma de Bucaramanga, UNAB y de la Escuela de Filosofía, Universidad Industrial de Santander, UIS, vinculada al grupo de investigación Politeia. Contacto: apabon742@unab.edu.co 


\section{RESUMEN}

La distinción entre esfera pública informal y esfera institucional es clave en la propuesta de Jürgen Habermas acerca del rol de la religión en la esfera pública. Este texto se pregunta por el carácter informal o institucional de las intervenciones ciudadanas y conceptos técnicos que se presentan en las acciones públicas de inconstitucionalidad. Para ello, se analiza la sentencia C-355-06, centrándose en aquellas intervenciones y conceptos con contenido religioso. El análisis permite concluir que es necesario que el ámbito de las intervenciones se considere como un espacio mixto, pues la teoría democrática de Habermas requiere que la deliberación sea amplia e incluyente.

Palabras clave: Esfera pública; esfera institucional; tribunales constitucionales; intervención ciudadana; proceso de inconstitucionalidad. 


\section{ABSTRACT}

The distinction between the informal public sphere and the institutional sphere is vital for Jürgen Habermas' proposal related to the role of religion in the public sphere. This text questions the informal or institutional character of citizen interventions and technical concepts presented in public unconstitutionality actions. For this purpose, we analyze sentence C-355-06, focusing on those interventions and concepts with a religious content. This analysis allows us to conclude that it is necessary for the intervention space to be considered as a mixed space, since Habermas' democratic theory requires the discussion to be comprehensive and inclusive.

Keywords: public sphere; institutional sphere; constitutional court; citizen intervention; unconstitutionality process

\section{SUMARIO}

INTRODUCCIÓN.- I. LA PROPUESTA DE HABERMAS SOBRE EL ROL DE LA RELIGIÓN EN LA ESFERA PÚBLICA.- II. LA NOCIÓN DE DEMOCRACIA DELIBERATIVA Y EL ROL DE LA DELIBERACIÓN EN LAS DECISIONES DE LOS TRIBUNALES CONSTITUCIONALES.- III. LA NATURALEZA Y EL VALOR DE LAS INTERVENCIONES CIUDADANAS en los PRocesos de Constitucionalidad en Colombia.- $A$. Los límites de la participación ciudadana mediante las intervenciones en los procesos de inconstitucionalidad.- IV. ANÁLISIS DEL PROBLEMA CONCRETO: EL CARÁCTER INSTITUCIONAL O INFORMAL DE LAS INTERVENCIONES CIUDADANAS Y LOS CONCEPTOS ESPECIALIZADOS EN LA SENTENCIA C-355-06.- A. Intervenciones y conceptos a favor de la liberalización de la IVE.- B. Intervenciones y conceptos en defensa de la norma que sanciona penalmente la IVE.- CoNCLUSIONES.- BiBLIOGRAFÍA. 


\section{INTRODUCCIÓN}

Para muchos analistas, la Constitución Política de $1991^{1}$ representa la realización, para Colombia, de un Estado constitucional en el cual los derechos fundamentales se convierten en criterios definitorios de lo correcto o incorrecto desde el punto de vista jurídicopolítico. Los derechos fundamentales aparecen como contenidos vivos que deberían limitar, condicionar y servir de fuente para la interpretación y la aplicación del Derecho. Desde esta perspectiva, todo el poder del Estado - expresado en la actividad de sus ramas legislativa, ejecutiva y judicial — debe ser sometido a la razón expresada en la Constitución; es decir, la razón pública constitucional.

La Corte Constitucional ha adquirido un gran valor a la hora de determinar las orientaciones que tendrá el desarrollo de la vida social, política, económica y cultural del país. Esto explica, entonces, por qué precisamente en el seno de su actividad interpretativa jurisprudencial se concentran de manera privilegiada los más álgidos y difíciles debates en torno a los asuntos más significativos de la sociedad y la política.

El eje problemático de esta investigación es esta actividad interpretativa de la Corte Constitucional colombiana, «expresión de la razón pública $»^{2}$, frente a los debates jurídicos, políticos y sociales que se llevan a cabo en este país ${ }^{3}$. Esta pregunta de investigación hace referencia al tipo de argumentos que en ella prevalecen, fundamentalmente en lo atinente a los argumentos de carácter religioso que forman parte de nuestra realidad epistémica y discursiva social y política.

De hecho, en nuestra tradición histórica hemos mantenido un fuerte vínculo entre religión y política, tradición que, no obstante, ha sido obligada a dinamizarse luego de la Constitución de 1991. En esta Constitución, a partir del establecimiento del principio del pluralismo, se ha construido todo un discurso jurídico-político a favor de la laicidad en el orden constitucional y legal y se han forta-

1 Colombia, Constitución Política, 4 de julio de 1991, 116 Gaceta Constitucional, segunda edición corregida, 20 de julio de 1991. Disponible en: http://www.secretariasenado.gov.co/senado/ basedoc/constitucion_politica_1991.html

2 John Rawls, Liberalismo politico, 220 (Fondo de Cultura Económica, México, 1996).

3 Esta fue la pregunta general de la investigación. En este artículo no analizamos los argumentos de la Corte, sino los de los intervinientes. 
lecido las tendencias seculares de las corrientes políticas y sociales, divergentes y alternativas al orden preestablecido.

La reflexión contenida en este artículo producto de investigación obedece a una estructura metodológica que tiene como base la descripción de los resultados del análisis crítico de los distintos discursos expuestos por los intervinientes en el debate constitucional en el caso de la sentencia C-355-06 . Este análisis se aborda desde un horizonte cualitativo con el fin de identificar, a partir de los criterios establecidos con base en el referente teórico propuesto, la perspectiva que orienta la presentación de los argumentos de los intervinientes en el debate constitucional en torno a la liberalización de la interrupción voluntaria del embarazo, IVE.

Para el desarrollo del problema se ha realizado un análisis de la sentencia en cuestión de la siguiente manera. En primer lugar, se presenta brevemente la propuesta de JÜRGEN HABERMAS acerca del rol de la religión en la esfera pública. En segundo lugar, se expondrán la noción de democracia deliberativa de HABERMAS y el rol de la deliberación en las decisiones judiciales. Luego, se analizarán las intervenciones ciudadanas y los conceptos que se expresaron en la sentencia C-355-06, y, finalmente, se proponen algunas conclusiones.

\section{LA PROPUESTA DE HABERMAS SOBRE EL ROL DE LA RELIGIÓN EN LA ESFERA PÚBLICA}

El problema de las relaciones conflictivas y complementarias entre las religiones y los Estados constitucionales ha captado el interés de una gran variedad de filósofos de diferentes tradiciones. Entre estos filósofos se destaca JürGEN HABERMAS, quien recientemente ha presentado una revaloración del papel de la religión en el marco de sus observaciones sobre la modernidad y la democracia ${ }^{5}$.

4 Corte Constitucional, Sentencia C-355-06, 10 de mayo de 2006, magistrados ponentes Jaime Araújo-Rentería \& Clara Inés Vargas-Hernández. Disponible en: http://www.corteconstitucional. gov.co/relatoria/2006/C-355-06.htm

5 En la literatura nacional e internacional, se identifican importantes trabajos que analizan el "giro habermasiano" de la religión. Entre otros, JAVIER AgUIRre, Habermas y la religión en la esfera pública, 61 Revista Ideas y Valores, 148, 59-78 (2012). Disponible en: http://www.redalyc. org/pdf/809/80924112004.pdf. Javier Aguirre, Habermas' Account of the Role of Religion in the Public Sphere: a Response to Cristina Lafont's Critiques through an Illustrative Political Debate about Same Sex Marriage, 39 Philosophy and Social Criticism, 7, 637-673 (2013). AN- 
HABERMAS se interesa por el problema del rol de la religión en las sociedades democráticas contemporáneas en el marco del papel que desempeñan las deliberaciones libres e informadas en la legitimación de un sistema político democrático en el cual los ciudadanos tienen que concebirse a sí mismos, y actuar en consecuencia, no solo como sujetos de las leyes que los rigen sino como sus autores. Para Habermas,

El procedimiento democrático debe su fuerza generativa de legitimación a dos componentes: por un lado, a la participación politica igualitaria de los ciudadanos, que garantiza que los destinatarios de las leyes puedan también entenderse a sí mismos al mismo tiempo como los autores de esas leyes; $y$, por otro lado, a la dimensión epistémica de las formas de discusión y de acuerdo

DREA BAUMeISTER, The Use of "Public Reason" by Religious and Secular Citizens: Limitations of Habermas' Conception of the Role of Religion in the Public Realm, 18 Constellations, 2, 222-243 (2011). Richard Bernstein, Naturalism, Secularism, and Religion: Habermas's Via Media, 17 Constellations, 1, 155-166 (2010). James W. Boettcher, Habermas, Religion and the Ethics of Citizenship, 35 Philosophy \& Social Criticism, 1-2, 215-238 (2009). Antonio Cerella, Religion and the Political Form: Carl Schmitt's Genealogy of Politics as Critique of Jürgen Habermas' Post-Secular Discourse, 38 Review of International Studies, 5, 975-994 (2012). Simone Chambers, How Religion Speaks to the Agnostic: Habermas on the Persistent Value of Religion, 14 Constellations, 2, 210-223 (2007). MAEve Cooke, Salvaging and Secularizing the Semantic Contents of Religion: the Limitations of Habermas's Postmetaphysical Proposal, 60 International Journal of Philosophy of Religion, 1, 187-207 (2006). Maeve Cooke, A Secular State for a Postsecular Society? Postmetaphysical Political Theory and the Place of Religion, 14 Constellations, 2, 224-238 (2007). Juan Antonio Estrada, Por una ética sin teología. Habermas como filósofo de la religión (Trotta, Madrid, 2004). JuAn Antonio estrada, Razón, lenguaje y religión, 226 Proyección: Teología y mundo actual, 223-232 (2007). Iván GARzón-VALlejo, Los dilemas del carácter público de los argumentos filosóficos y religiosos en el liberalismo de John Rawls, 30 Praxis Filosófica, 39-63 (2010). Disponible en: http://www.redalyc.org/pdf/2090/209019322003. pdf. Iván Garzón-VAllejo, Deliberación democrática y razones religiosas: objeciones y desafíos, 9 Revista Co-herencia, 16, 81-117 (2012). Disponible en: http://publicaciones.eafit.edu. co/index.php/co-herencia/article/view/1181/1068. GuILlermo HoYos-VÁsQuez \& EduARdo A. Rueda-BArrera, eds., Filosofía política: entre la religión y la democracia (Editorial Pontificia Universidad Javeriana, Bogotá, 2011). Julieta Lemaitre-Ripoll, Anti-clericales de nuevo: La Iglesia Católica como un actor político ilegítimo en materia de sexualidad y reproducción en América Latina, en Derecho y Sexualidades, 286-304 (Marcelo Alegre, Karina Ansolabehere, Antonio Bascuñán-Rodríguez, Bo Burt, Jaime Couso, Ana Maria de Oliveira-Nusdeo, Carlos Alberto de Salles, Mónica González-Contró, lucas S. Grosman, Isabel C. Jaramillo, Julieta Lemaitre-Ripoll, Alejandro Madrazo, Fernando Muñoz L., Catalina PérezCorrea, Lourdes Peroni, Francisca Pou-Giménez, Mario Ramos-Reyes, Laura Saldivia, Reva B. Siegel, Esther Vicente \& Kenji Yoshin, Libraria, Buenos Aires, 2009). Disponible en: https://www.academia.edu/3862378/LEMAITRE_RIPOLL_J._Anticlericales_de_nuevo_la_Iglesia_Cat $\%$ C3\%B3lica_como_un_actor_ileg\%C3\%ADtimo_en_sexualidad_y_ reproducci $\%$ C3\%B3n_en_Am $\%$ C3\%A9rica_Latina_en_Derecho_y_Sexualidades_ed._Lourdes_Peroni._Libraria_Buenos_Aires_2010. AAKASH SInGH, Habermas' Wrapped Reichstag: Limits and Exclusions in the Discourse of Post-Secularism, 20 European Review, 1, 131-147 (2012). Darren R. Walhof, Habermas, Same-Sex Marriage and the Problem of Religion in the Public Life, 39 Philosophy \& Social Criticism, 3, 225-242 (2013). 
dirigidas deliberativamente, que justifican la presunción de resultados racionalmente aceptables ${ }^{6}$.

En virtud de lo anterior, en las discusiones públicas desarrolladas en la "esfera pública informal", los ciudadanos religiosos deberían poder expresar y justificar sus convicciones en un lenguaje religioso si no pueden encontrar traducciones seculares para ellas. Pero esto, de acuerdo con HABERMAS, tiene un corolario referido a los ciudadanos seculares: tienen que abrir su mente a los posibles contenidos de verdad de tales presentaciones. Este aspecto implicaría, por lo menos, los siguientes tres deberes para los ciudadanos seculares: primero, no podrían controvertir el derecho de los ciudadanos creyentes de hacer contribuciones a los debates políticos públicos expresadas en un lenguaje religioso. Segundo, no podrían negar, a priori, el potencial de verdad de las concepciones religiosas del mundo. Y, tercero, se esperaría incluso que participaran en los esfuerzos por traducir las contribuciones relevantes de un lenguaje religioso a uno públicamente accesible ${ }^{8}$. Se espera que los ciudadanos seculares no adopten una actitud secularista, es decir, aquella que le niega todo valor a la religión y la considera, si acaso, una "reliquia del pasado".

En el caso de los ciudadanos religiosos, Habermas también especifica tres deberes, reflejo de los desafíos que la modernidad les ha planteado a las conciencias religiosas: los ciudadanos religiosos deben desarrollar una actitud epistémica que les permita aceptar la existencia y validez de otras religiones; reconocer la independencia y autonomía del conocimiento secular y; reconocer que la primacía última de las razones seculares en la arena política se deriva

JÜrgen Habermas, Entre naturalismo y religión, 128 (Paidós, Madrid, 2006).

7 El concepto de "esfera pública informal" hace parte del lenguaje filosófico de HaBERMAS con el cual desarrolla su noción de democracia deliberativa. La expresión "esfera pública formal", por contraste, no hace parte en estricto sentido del edificio conceptual habermasiano. Es una expresión presentada por la filósofa española CRISTINA LAFONT para desarrollar su interpretación crítica de la propuesta de Habermas. Cristina Lafont, Religion in the Public Sphere: Remarks on Habermas' Conception of Public Deliberation in Post-secular Societies, 14 Constellations, 2, 239-259 (2007). Cristina Lafont, Religion in the Public Sphere, 35 Philosophy \& Social Criticism, 1-2, 127-150 (2009). Acá la incluimos ya que resulta bastante útil para entender y explicar el alcance de la perspectiva de HABERMAS.

8 Jürgen Habermas, Entre naturalismo y religión (Paidós, Madrid, 2006).

9 Jürgen Habermas, ;Ay, Europa! Pequeños escritos politicos, 77 (Trotta, Madrid, 2009). 
del individualismo igualitario del Derecho racional y de la moral universalista.

Ahora bien, a pesar de esta apertura hacia la religión, HABERMAS mantiene la tradición liberal en la "esfera pública formal", esto es, en el mismo rango institucional del congreso, los jueces, las cortes $\mathrm{y}$, en general, la administración pública. En esta esfera, todo tiene que ser expresado en un lenguaje accesible a todos los ciudadanos. Ningún argumento religioso sería aceptable para justificar o expresar alguna ley o política aplicable a todos los ciudadanos. Lo mismo puede decirse de la fundamentación y el lenguaje que deben tener las decisiones judiciales.

En este punto, HABERMAS coincide enteramente con JOHN RAWLS. En efecto, para RAwLs, la Suprema Corte "constituye el más alto ejemplo de la razón pública aplicada" 10 y en este sentido, en el marco de una democracia constitucional, en la que hay revisión judicial, sus decisiones deben ser explicadas y justificadas con base en "(...) su conocimiento y comprensión de la Constitución y en los estatutos y casos precedentes"11.

Esta idea ha sido retomada en las actuaciones de la Corte Constitucional de Colombia. No en vano esta misma corporación en sus jurisprudencias ha afirmado el carácter laico del Estado colombiano, en especial, a partir del principio constitucional del pluralismo. Por esto, en el desarrollo de la investigación fue relevante la pregunta acerca de la postura de la Corte Constitucional de Colombia en relación con los argumentos religiosos a la hora de fundamentar y expresar sus decisiones en algunos casos controvertidos.

Sin lugar a dudas, las discusiones judiciales que se llevan a cabo en los procesos de constitucionalidad hacen parte del ámbito institucional de la esfera pública colombiana. Sin embargo, también son discusiones que desbordan el ámbito del razonamiento meramente jurídico. Como lo ha señalado la misma Corte Constitucional:

El derecho que sustenta la posibilidad de instaurar acciones públicas de inconstitucionalidad es de naturaleza política, y tiene por objeto la preservación del orden institucional en sí mismo, con independencia de intereses individuales propios o ajenos, lo que significa que está reservada a los nacionales colom-

10 John Rawls, Liberalismo politico, 207 (Fondo de Cultura Económica, México, 1996).

11 John Rawls, Liberalismo político, 207 (Fondo de Cultura Económica, México, 1996). 
bianos y, entre estos, a quienes hayan alcanzado la ciudadanía y estén en el ejercicio de ella ${ }^{12}$.

Por esta razón, los procesos de constitucionalidad incluyen un momento en que las deliberaciones parecen tener una naturaleza diferente. Es el caso del escenario de las intervenciones ciudadanas, previstas en el artículo 242, numeral 1 de la Constitución Política, como un espacio para que los ciudadanos presenten argumentos en los procesos de inconstitucionalidad con el fin de impugnar o defender la norma sometida a control.

La participación de los ciudadanos está desprovista de mayores exigencias y formalismos, para asegurar el ejercicio del derecho a participar $^{13}$. El escenario de las intervenciones ciudadanas en los procesos de constitucionalidad puede ser útil para llamar la atención acerca de una cuestión problemática que encontramos en la propuesta de HABERMAS acerca del rol de la religión en la esfera pública. Se trata de la distinción que hace entre una esfera pública informal y una esfera institucional.

Esta distinción, fundamental en la propuesta de HABERMAS, parece ser mucho más porosa de lo que su perspectiva presupone. Esta porosidad se puede ver en el mencionado ámbito de las intervenciones ciudadanas en los procesos de constitucionalidad. En principio, parece ser una esfera formal-institucional ya que se trata de un proceso jurídico. Si esto es así, siguiendo la propuesta de Habermas, no se debería admitir ningún tipo de lenguaje religioso. Por ende, si un ciudadano interviniera haciendo uso de argumentos religiosos, el magistrado ponente debería estar facultado para no incluir en el debate ese tipo de intervenciones.

Sin embargo, si tenemos en cuenta la finalidad de las intervenciones, a saber, permitir la participación ciudadana de la forma más amplia posible, parece que podemos afirmar que en realidad se trata de un ámbito propio de la esfera pública informal. En consecuencia, los ciudadanos podrían participar con argumentos

12 Corte Constitucional, Sentencia C-536-98, 1 de octubre de 1998, magistrado ponente José Gregorio Hernández-Galindo. Disponible en: http://www.corteconstitucional.gov.co/ RELATORIA/1998/C-536-98.htm

13 Corte Constitucional, Auto 035-98, 15 de julio de 1998, magistrado ponente José Gregorio Hernández-Galindo. Disponible en: http://www.corteconstitucional.gov.co/relatoria/Autos/ 1998/A035-98.htm 
religiosos si así lo desean. Esto obligaría a que los magistrados tuvieran que tomar en serio estos argumentos religiosos so pena de volverlos banales y fútiles.

Este es pues el problema concreto que nos interesa analizar en este texto, el cual podría formularse de la siguiente forma: ¿las intervenciones ciudadanas propuestas en los procesos de constitucionalidad son argumentaciones que se desarrollan en un ámbito formal-institucional o, por el contrario, en un ámbito informal? Para desarrollar nuestro análisis, acudiremos a las intervenciones de la sentencia C-355-06, un caso que contó con una gran cantidad de intervenciones ciudadanas. Antes de esto, sin embargo, presentaremos la posición de HABERMAs sobre el rol de la deliberación en las decisiones de los tribunales constitucionales.

\section{LA NOCIÓN DE DEMOCRACIA DELIBERATIVA Y EL ROL DE LA DELIBERACIÓN EN LAS DECISIONES DE LOS TRIBUNALES CONSTITUCIONALES}

Las principales reflexiones de HABERMAS acerca del rol de los tribunales constitucionales se desprenden de su idea de democracia deliberativa. La mirada de HABERMAS está determinada por dos asuntos muy puntuales que hasta la fecha han orientado el debate sobre el rol de los tribunales constitucionales en una democracia, referidos a la indeterminación del Derecho y a la irracionalidad de la justicia.

Al respecto, Habermas asume en líneas generales la perspectiva de RonAld Dworkin acerca de la posibilidad de respuestas correctas en el Derecho. Sin embargo, como lo ha señalado ÓsCAR MejíA-Quintana, a Habermas le interesa mostrar que la perspectiva monológica del juez Hércules de DwORKIN debe ser corregida a partir de "una teoría discursiva del derecho en donde el solipsismo del súper juez sea reemplazado por la institucionalización de las presuposiciones y procedimientos comunicativos del discurso legal contemporáneo"14.

14 Óscar MeJía-Quintana, El dilema histórico de la decisión judicial: la teoría del derecho de Jürgen Habermas, 14 Revista Panameña de Política, 67-103 (2012). Disponible en: http://cidempanama. org/wp-content/uploads/2013/05/EL-dilema-hist $\%$ C3\%B3ricoRPP14.pdf 
Por esto, para HABERMAs, la principal función de los tribunales constitucionales es garantizar que los procedimientos comunicativos y deliberativos hayan permitido que los mejores argumentos hubieran sido los decisivos al momento de la toma de decisiones legislativas. Las normas controvertidas deben ser analizadas, en relación con los presupuestos comunicativos y las condiciones procedimentales del proceso democrático de producción de normas. En palabras de HABERMAS,

El criterio de enjuiciamiento es el carácter discursivo de la formación de la opinión y de la voluntad, en especial la cuestión de si en la decisión legislativa han resultado determinantes razones defendibles públicamente o intereses privados que no pueden declararse en el marco de las discusiones parlamentarias ${ }^{15}$.

De esta forma, la jurisprudencia constitucional tiene el deber último de hacer respetar el procedimiento democrático y la forma deliberativa de formación de la opinión y de la voluntad política. En especial, los tribunales deben estar atentos a sacar a la luz, tras los objetivos e intereses políticamente relevantes, los intereses y orientaciones valorativas "que de ningún modo pueden considerarse ingrediente constitutivo de la identidad de la comunidad en conjunto, es decir, del conjunto, de una forma de vida intersubjetivamente compartida" 16

Un corolario de lo anterior es que la ciudadanía debe ser entendida por los tribunales constitucionales como los ojos críticos de un espacio público-político jurídico politizado en el cual los ciudadanos también hacen parte de la comunidad de intérpretes de la Constitución. En el paradigma deliberativo de la democracia, los ciudadanos no son concebidos como meros participantes privados y egoístas en el mercado de bienes y servicios (derechos incluidos), ni como simples clientes pasivos de las burocracias del Estado social. Los ciudadanos, en contraste, son agentes activos que toman parte "en discursos políticos para hacer valer intereses vulnerados, y que por vía de la articulación de esos intereses cooperan en el desarrollo

15 Jürgen Habermas, Facticidad y validez: sobre el derecho y el estado democrático de derecho en términos de teoría del discurso, 350 (Trotta, Madrid, 1998).

16 Jürgen Habermas, Facticidad y validez: sobre el derecho y el estado democrático de derecho en términos de teoría del discurso, 357 (Trotta, Madrid, 1998). 
de criterios concernientes al trato igual de los casos iguales y al trato desigual de los casos desiguales"17.

Por todo lo anterior, para HABERMAS, es simplemente inevitable que las decisiones de los tribunales se produzcan en una zona gris entre la producción legislativa y la aplicación del derecho. La complejidad de las sociedades contemporáneas y la necesidad de concreción que tienen todas las leyes implican que en muchas ocasiones las decisiones de los tribunales constitucionales tengan una "vocación cuasi legisladora". La respuesta a esta realidad no puede ser la actitud negadora que pretende que los jueces constitucionales se adecúen a modelos silogísticos deductivistas imposibles de seguir. Tampoco se puede esperar que el juez constitucional intente adoptar modelos de democracia restringidos, como el modelo liberal de la democracia formal o el modelo republicano de la democracia directa. En contraste, para HABERMAS, el juez constitucional debe reconocer que el mejor modelo es el de la democracia deliberativa. En este, como señala ÓsCAR MEJÍA-Quintana: "El alter ego del tribunal constitucional no son los meros procedimientos democráticos (democracia formal) ni la voluntad de las mayorías (democracia directa) sino la deliberación ciudadana que se manifiesta en la dinámica comunicativa de la esfera pública"18.

La carga de legitimación adicional que requiere la labor de los tribunales constitucionales se solventa, al menos de forma parcial, si se obliga institucionalmente a la justicia "a dar justificaciones ante un foro ampliado de críticos de ella"19. Las funciones de esclusas sistémicas de los tribunales, en virtud de las cuales conectan las demandas provenientes del mundo de la vida de las sociedades contemporáneas con las exigencias sistémicas de los Estados modernos, solo se pueden desarrollar cabalmente si la sociedad civil es capaz de influenciar la labor de los tribunales constitucionales ${ }^{20}$.

17 Jürgen Habermas, Facticidad y validez: sobre el derecho y el estado democrático de derecho en términos de teoría del discurso, 525 (Trotta, Madrid, 1998).

18 Óscar Mejía-Quintana, El dilema histórico de la decisión judicial: la teoría del derecho de Jürgen Habermas, 14 Revista Panameña de Política, 67-103, 101 (2012). Disponible en: http:// cidempanama.org/wp-content/uploads/2013/05/EL-dilema-hist \%C3\%B3ricoRPP14.pdf

19 Jürgen Habermas, Facticidad y validez: sobre el derecho y el estado democrático de derecho en términos de teoría del discurso, 526 (Trotta, Madrid, 1998).

20 HABERmas usa el término "influencia" en un sentido especializado derivado de la teoría social de Talcott Parsons. Cfr. Jürgen Habermas, Facticidad y validez: sobre el derecho y el estado democrático de derecho en términos de teoría del discurso, 443 (Trotta, Madrid, 1998). 
En palabras de HABERMAS: "En este sentido, las opiniones públicas representan un potencial político de influencia que puede utilizarse para ejercer influencia sobre el comportamiento electoral de los ciudadanos o sobre la formación de la voluntad en los organismos parlamentarios, en los gobiernos y en los tribunales" 21 .

En resumen, para Habermas, el juez constitucional debe ser concebido como un intérprete de textos jurídico-políticos así como también de contextos sociopolíticos. En este sentido, los ciudadanos democráticos también deben concebirse como intérpretes constitucionales que, por lo tanto, deben ser tenidos en cuenta por los tribunales.

Naturalmente, cada democracia debe enfrentar el reto de encontrar el mejor diseño institucional para especificar lo anterior en su propio contexto sociocultural. En el caso de la democracia colombiana, una forma mediante la cual se ha intentado implementar lo anterior es la posibilidad de realizar intervenciones ciudadanas en los procesos de constitucionalidad.

\section{LA NATURALEZA Y EL VALOR DE LAS INTERVENCIONES CIUdAdANAS EN LOS PROCESOS DE CONSTITUCIONALIDAD EN COLOMBIA}

Colombia adoptó un control público de constitucionalidad en el que los ciudadanos pueden demandar las normas que consideren contrarias al ordenamiento constitucional o de oficio hacer juicios de constitucionalidad previos a la sanción de la ley. Además de la demanda, la Constitución permite que los ciudadanos puedan intervenir como impugnadores o defensores de las normas sometidas a control. El Decreto 2067 de $1991^{22}$ fija el procedimiento en las acciones públicas de inconstitucionalidad y señala la oportunidad para que los ciudadanos intervengan.

21 Jürgen Habermas, Facticidad y validez: sobre el derecho y el estado democrático de derecho en términos de teoría del discurso, 443 (Trotta, Madrid, 1998).

22 Colombia, Decreto 2067 de 1991, por el cual se dicta el régimen procedimental de los juicios y actuaciones que deban surtirse ante la Corte Constitucional, 40.012 Diario Oficial, 4 de septiembre de 1991. Disponible en: http://www.secretariasenado.gov.co/senado/basedoc/ decreto_2067_1991.html 
En el auto que admite la demanda, se ordena divulgar las normas demandadas para que en el término de diez días cualquier ciudadano se pronuncie. De igual forma, los ciudadanos intervinientes pueden ser citados a participar en las audiencias públicas convocadas por cualquier magistrado.

La acción pública de inconstitucionalidad es significativa en el contexto democrático y fue propuesta por el Constituyente "no solo para que los ciudadanos puedan impugnar o defender la norma sometida a control, garantía de la participación ciudadana, sino, además, con el propósito de que estos le brinden al juez constitucional elementos de juicio adicionales que le permitan adoptar una decisión" "23.

\section{A. Los límites de la participación ciudadana mediante las intervenciones en los procesos de inconstitucionalidad}

La participación ciudadana mediante las intervenciones está desprovista de mayores formalismos o ritualidades. Los únicos requisitos formales para intervenir son ostentar la calidad de ciudadano y presentar la intervención a tiempo ${ }^{24}$. Sin embargo, la Corte Constitucional en distintos pronunciamientos ha establecido que la participación está limitada por el ámbito mismo de la demanda de inconstitucionalidad en dos sentidos que pueden considerarse materiales. El primero, referido al contenido de las intervenciones, el cual debe limitarse a los cargos propuestos por el accionante y

23 Corte Constitucional, Auto 243-01, 11 de julio de 2001, magistrado ponente Jaime CórdobaTriviño. Disponible en: http://www.corteconstitucional.gov.co/relatoria/Autos/2001/A243-01. $\mathrm{htm}$

24 Corte Constitucional de Colombia, Sentencia C-915-01, 29 de agosto de 2011, magistrado ponente Eduardo Montealegre-Lynett. Disponible en: http://www.corteconstitucional.gov. co/relatoria/2001/C-915-01.htm. Por esa razón, la Corte no ha tenido en cuenta intervenciones presentadas en forma extemporánea o por extranjeros. Esto se reitera en Corte Constitucional, Auto 035-97, 2 de octubre de 1997, magistrado ponente Carlos Gaviria-Díaz. Disponible en: http://www.corteconstitucional.gov.co/relatoria/autos/1997/A035-97.htm. Corte Constitucional, Auto 243-01, 11 de julio de 2001, magistrado ponente Jaime Córdoba-Triviño. Disponible en: http://www.corteconstitucional.gov.co/relatoria/Autos/2001/A243-01.htm. Corte Constitucional, Auto 251-01, 17 de julio de 2001, magistrado ponente Jaime Córdoba-Triviño. Disponible en: http://www.corteconstitucional.gov.co/relatoria/Autos/2001/A251-01.htm. Corte Constitucional, Auto 054-04, 4 de mayo de 2004, magistrado ponente Eduardo MontealegreLynett. Disponible en: http://www.corteconstitucional.gov.co/relatoria/Autos/2004/A054-04. htm 
el segundo, referido a la coherencia de la intervención con la naturaleza de la acción de inconstitucionalidad, a saber, la interpretación y juzgamiento de la norma acusada a la luz del ordenamiento constitucional.

Sobre lo primero, la Corte ha señalado que las intervenciones no constituyen una nueva demanda. No se deben formular cargos adicionales a los planteados por el demandante ${ }^{25}$. Por ende, la Corte no está obligada a analizar los cargos nuevos que formula un interviniente ${ }^{26}$.

Los cargos que ha propuesto el accionante constituyen un límite material; los intervinientes solo pueden manifestar su acuerdo o desacuerdo con los cargos de la demanda propuestos por el accionante o en la objeción presidencial por inconstitucionalidad, salvo que se invoque la existencia de una unidad normativa con la norma demandada ${ }^{27}$.

Para la Corte:

(...) dado que la vía de la acción pública es un instrumento democrático de control de los ciudadanos, no sometido a mayores formalismos, por un lado, el cumplimiento de los mínimos establecidos por el ordenamiento jurídico debe ser estricto, $y$, por otro, si es voluntad del interviniente la de formular una nueva demanda sobre la disposición acusada o sobre otras, debe presentarla conforme a los requisitos exigidos y someterse al trámite legal correspondiente ${ }^{28}$.

Este límite no existe en los procesos de inconstitucionalidad de oficio, en los cuales las intervenciones ciudadanas pueden referirse a la totalidad de la norma objeto de control.

Ahora bien, sobre el segundo límite material referido a la naturaleza de la acción, la Corte ha señalado que "el control de constitucionalidad no es el escenario para los análisis de conveniencia en

25 Corte Constitucional, Auto 243-01, 11 de julio de 2001, magistrado ponente Jaime CórdobaTriviño. Disponible en: http://www.corteconstitucional.gov.co/relatoria/Autos/2001/A243-01. htm

26 Corte Constitucional, Sentencia C-194-13, 10 de abril del 2013, magistrado ponente Luis Ernesto Vargas-Silva. Disponible en: http://www.corteconstitucional.gov.co/ RELATORIA/2013/C-194-13.htm

27 Corte Constitucional, Sentencia C-1155-05, 15 de noviembre de 2005, magistrado ponente Rodrigo Escobar-Gil. Disponible en: http://www.corteconstitucional.gov.co/ relatoria/2005/C-1155-05.htm

28 Corte Constitucional, Sentencia C-1187-05, 22 de noviembre de 2005, magistrado ponente Humberto Antonio Sierra-Porto. Disponible en: http://www.corteconstitucional.gov.co/ relatoria/2005/C-1187-05.htm 
torno a las normas jurídicas, ni para la discusión de las alternativas que a los intervinientes les parezcan mejores o, incluso, más adecuadas al orden constitucional" 29 . Las discusiones políticas tendientes a generar cambios en la ley tienen como espacio para su desarrollo el Congreso de la República y no el control de constitucionalidad.

Parece que estas son las únicas limitaciones que el ordenamiento jurídico y la interpretación de la Corte han sugerido en materia de intervenciones ciudadanas. Sin embargo, en la sentencia C-194-1330, la Corte hace una manifestación en torno al contenido de los argumentos que pueden presentarse. En este proceso, los intervinientes incluyen en su argumentación un cargo que el accionante no propuso, manifestando que la norma que penaliza actos de discriminación por razones de orientación sexual afecta la libertad religiosa, "en especial de la población que profesa el catolicismo, pues penaliza algunas de sus posiciones doctrinarias, que a la luz de la norma demandada recaerían injustamente en el criterio de discriminación"31.

En el mismo sentido se pronuncia la Universidad La Gran Colombia que ataca la inconstitucionalidad de la norma al no tener en cuenta el supuesto carácter teísta de la moral contenida en la Constitución. La Corte, al examinar los cargos de la demanda, encuentra que los accionantes no motivaron en debida forma el cargo contra la libertad religiosa y que pese a que algunos intervinientes se refirieron a este cargo, se excluye por falta de motivación. La Corte mantiene su línea de decisiones que limita el contenido de las intervenciones a los cargos señalados por los accionantes ${ }^{32}$. Adicionalmente, sin embargo, la Corte también afirma que la justificación presentada en la intervención ciudadana "se limita" a afirmar que la norma penal acusada "se opone a la libertad de

29 Corte Constitucional, Sentencia C-1155-05, 15 de noviembre de 2005, magistrado ponente Rodrigo Escobar-Gil. Disponible en: http://www.corteconstitucional.gov.co/ relatoria/2005/C-1155-05.htm

30 Corte Constitucional, Sentencia C-194-13, 10 de abril del 2013, magistrado ponente Luis Ernesto Vargas-Silva. Disponible en: http://www.corteconstitucional.gov.co/ RELATORIA/2013/C-194-13.htm

31 Corte Constitucional, Sentencia C-194-13, 10 de abril del 2013, magistrado ponente Luis Ernesto Vargas-Silva, intervenciones ciudadanas. Disponible en: http://www.corteconstitucional. gov.co/RELATORIA/2013/C-194-13.htm

32 Corte Constitucional, Sentencia C-194-13, 10 de abril del 2013, magistrado ponente Luis Ernesto Vargas-Silva. Disponible en: http://www.corteconstitucional.gov.co/ RELATORIA/2013/C-194-13.htm 
expresión, en especial la difusión de las ideas propias de la religión católica, pero tampoco ofrecen argumentos sustantivos sobre esa precisa materia" 33 .

Esta última afirmación de la Corte permitiría sostener que las intervenciones ciudadanas, pese a que no tienen mayores formalismos una vez se integran al proceso, deben asumir la carga de la argumentación con el fin de que se incorporen al debate razones que permitan orientar la discusión que se libra en el escenario constitucional. Esto supone que no podrían simplemente estar compuestas por meras afirmaciones.

Pero ¿qué significa que una intervención contenga "meras afirmaciones sin argumentos sustantivos"? ¿Estas exigencias se promueven por tratarse, en el presente caso de una intervención con contenido religioso? En otras palabras, ¿está la Corte afirmando que los argumentos religiosos son meras afirmaciones que los intervinientes tienen que traducir en un lenguaje secular si quieren presentar realmente "argumentos sustantivos"?

Si es así, la Corte Constitucional estaría asumiendo la que, según HABERmas, es la perspectiva de RAWLs sobre el rol de la religión en la esfera pública. En efecto, RAwLS parece afirmar que es posible introducir, en las discusiones públicas, doctrinas y argumentos religiosos si y solo si en su debido momento se presentan también razones propiamente políticas y no razones enteramente basadas en las doctrinas religiosas ${ }^{34}$. Esto significa que, además del argumento religioso, el ciudadano religioso debe estar preparado para presentar otro argumento que no dependa completamente en su fe. Esto se conoce como la condición (proviso) de RAWLS.

33 Corte Constitucional, Sentencia C-194-13, 10 de abril del 2013, magistrado ponente Luis Ernesto Vargas-Silva, consideraciones y fundamentos, 4. Disponible en: http://www.corteconstitucional. gov.co/RELATORIA/2013/C-194-13.htm

34 John Rawls, The Idea of Public Reason Revisited, 64 The University of Chicago Law Review, 3, 765-807, 783 (1997). Disponible en: http://www.hartsem.edu/academic/courses/summer2009/ Idea $\% 20$ of $\% 20$ Public $\% 20$ Reason $\% 20$ Revisted $\% 20$ (Rawls).pdf 


\section{ANÁLISIS DEL PROBLEMA CONCRETO: EL CARÁCTER INSTITUCIONAL O INFORMAL DE LAS INTERVENCIONES CIUDADANAS $Y$ LOS CONCEPTOS ESPECIALIZADOS EN LA SENTENCIA C-355-06 ${ }^{35}$}

Ahora se describirán las intervenciones y conceptos que incluyeron argumentos religiosos. Se valorará si en el presente caso, la distinción propuesta por HABERMAS entre una esfera pública informal y una esfera institucional es pertinente, o si, por el contrario, en el escenario de las intervenciones ciudadanas en un caso como el analizado resulta porosa y problemática. Los argumentos se expondrán en dos grupos: aquellos a favor de la liberalización de la interrupción voluntaria del embarazo (IVE) y aquellos en contra. La distinción entre intervenciones y conceptos se hará a partir de las directrices reglamentarias, con base en la cual se puede afirmar que las intervenciones son manifestaciones a favor o en contra de la constitucionalidad de la norma acusada, hechas por ciudadanos colombianos, mientras que los conceptos son incorporados por expertos en el tema objeto de debate.

\section{A. Intervenciones y conceptos a favor de la liberalización de la IVE}

a. La Corporación Casa de la Mujer argumentó que la perspectiva que prohíbe de forma absoluta la interrupción voluntaria del embarazo y que otorga derechos fundamentales y personalidad jurídica al nasciturus asume una concepción moral absoluta y rígida acerca

35 Las intervenciones y conceptos se relacionan en el texto de la sentencia, en que se consigna "una síntesis de su contenido cuando hayan sido presentadas de manera oportuna". Corte Constitucional, Auto 257-09, 4 de agosto de 2009, magistrado ponente Gabriel Eduardo Mendoza-Martelo. Disponible en: http://www.corteconstitucional.gov.co/RELATORIA/ Autos/2009/A257-09.htm. Deben ser tenidos en cuenta en las deliberaciones y decisión final. Sin embargo, en casos altamente controvertidos como el de la liberalización de la interrupción voluntaria del embarazo, por la amplia concurrencia de intervinientes fue imposible hacer alusión a todas ellas en el texto final del fallo, pues en el proceso se presentaron más de 1.500 intervenciones. Corte Constitucional, Auto 360-06, Proceso de Nulidad contra la Sentencia C-355-06. Corte Constitucional, Auto 360-06, 6 de diciembre de 2006, magistrado ponente Clara Inés Vargas-Hernández. Disponible en: http://www.corteconstitucional.gov.co/relatoria/ Autos/2006/A360-06.htm. Corte Constitucional, Sentencia C-355-06, 10 de mayo de 2006, magistrados ponentes Jaime Araújo-Rentería \& Clara Inés Vargas-Hernández. Disponible en: http://www.corteconstitucional.gov.co/relatoria/2006/C-355-06.htm 
del valor intrínseco de la vida que el Estado no puede tomar como suya so pena de desconocer las libertades de conciencia y de religión.

b. La Corporación Cisma Mujer señala explícitamente que la prohibición del aborto vulnera el carácter laico del Estado colombiano. La Corporación recuerda que, a pesar de que bajo la Constitución de $1886^{36}$ el Estado colombiano se declaraba católico, la legislación penal que regía entre 1886 y 1980 permitía el aborto en ciertas circunstancias. La Corporación Cisma se refiere a los Códigos Penales de $1890^{37}$ y de $1936^{38}$, que admitían excepciones al delito de aborto. Estas excepciones se referían a salvar la vida de la mujer y también su honor.

La Corporación Cisma recuerda que, según la Constitución Política de 1991, el Estado colombiano es un Estado laico y pluralista; de ahí que si para una confesión religiosa el aborto resulta moralmente condenable, "el Estado no puede acoger esa creencia, promulgarla en una ley y hacerla obligatoria para toda la sociedad".

c. El defensor del pueblo recuerda que en sentencias anteriores (C-133-9499 y C-013-9740), la Corte asumió un sentido sagrado y absoluto de la vida humana, protegiendo de forma absoluta la vida del nasciturus. En contraste, en la sentencia C-239-9741, la Corte explícitamente señala que no está asumiendo a la vida como sagrada sino como digna, lo cual debe ser entendido desde una perspectiva secular y pluralista que respete la autonomía moral del individuo y las libertades y derechos constitucionales. Al hacer esta comparación, el Defensor del Pueblo pretende señalar las consecuencias

36 Colombia, Constitución Política de 1886, expedida el 1 de diciembre de 1885, proclamada el 5 de agosto de 1886. Disponible en: http://www.alcaldiabogota.gov.co/sisjur/normas/Norma1. jsp?i=7153

37 Colombia, Ley 19 de 1890, por la cual se expide el Código Penal, 18 de octubre de 1890. Disponible en: http://www.bdigital.unal.edu.co/6944/103/ley_19_de_1890_codigo_penal_libro_ primero.pdf

38 Colombia, Ley 95 de 1936, por la cual se expide el Código Penal, 24 de abril de 1936, 23.316 Diario Oficial, 24 de octubre de 1936. Disponible en: http://www.suin-juriscol.gov.co/viewDocument.asp?id=1791348

39 Corte Constitucional, Sentencia C-133-94, 17 de marzo de 1994, magistrado ponente Antonio Barrera-Carbonell. Disponible en: http://www.corteconstitucional.gov.co/ relatoria/1994/c-133-94.htm

40 Corte Constitucional, Sentencia C-013-97, 23 de enero de 1997, magistrado ponente José Gregorio Hernández-Galindo. Disponible en: http://www.corteconstitucional.gov.co/ RELATORIA/1997/c-013-97.htm

41 Corte Constitucional, Sentencia C-239-97, 20 de mayo de 1997, magistrado ponente Carlos Gaviria-Díaz. Disponible en: http://www.corteconstitucional.gov.co/relatoria/1997/c-239-97. htm 
de partir de un concepto de vida sagrada, entre las que se destaca la protección indeterminada que se hace de la vida, "independientemente de si existe o no certeza científica acerca del momento en que la vida humana inicia".

Por el contrario, cuando se parte de una concepción de la vida no sagrada o no religiosa, se afirma un espacio de decisión moral en que los individuos pueden construir su propia visión acerca del valor de la vida, la cual se entiende como una vida digna que cada cual desarrolla libremente según sus propias convicciones morales sin que el Estado pueda imponer determinada concepción religiosa.

Ahora bien, los anteriores argumentos - pese a ser referenciados en la sentencia como intervenciones - están propuestos por organizaciones que intervienen en calidad de expertos en el tema objeto de debate; desde ahí, pueden ser entendidos como conceptos. Todos ellos coinciden en señalar que el debate debe ir más allá de argumentos religiosos y están de acuerdo en el carácter restrictivo de la perspectiva religiosa.

Este grupo de argumentos insiste en tres elementos para la discusión: a) la vida no tiene un carácter sagrado; b) el Estado colombiano es un Estado laico; y, c) el Estado, en concordancia con lo anterior, no puede imponer la protección de la vida conforme a una determinada concepción religiosa. Todas estas intervenciones señalan el carácter restrictivo de la perspectiva religiosa.

En todo caso, no niegan de plano valor a las visiones religiosas de los ciudadanos pero asumen una postura que comprende que su inclusión en el debate está limitada. En concordancia con esta idea se puede analizar también el concepto del procurador.

f. El concepto del procurador general de la Nación señala que en temas como el aborto las más profundas concepciones éticas de las personas se encuentran en juego; por ende, es normal que la discusión incluya argumentos morales o religiosos. Sin embargo, estos argumentos, respetados y protegidos por el ordenamiento constitucional, no son pertinentes al momento de realizar el juicio de constitucionalidad.

Para la Procuraduría, es aceptable que los agentes estatales - incluidos los magistrados - indaguen sobre la perspectiva que frente a un determinado tema tienen todos los agentes de la sociedad y es válido que tales agentes expongan sus argumentos, religiosos o 
no, en procesos de constitucionalidad en el espacio para las intervenciones ciudadanas. Esto enriquece el debate público acerca del sentido del ordenamiento jurídico y amplía la visión de las cortes y las entidades estatales.

Con estas afirmaciones, el concepto del procurador se acerca a la tesis de HABERMAS de que los ciudadanos religiosos tienen derecho a hacer contribuciones a los debates políticos públicos expresadas en un lenguaje religioso. Igualmente, parece señalar que los espacios de intervención ciudadana en los procesos de constitucionalidad son procesos de argumentación informal en los cuales los argumentos religiosos tienen el derecho de ser expresados y oídos.

Sin embargo, el Ministerio Público considera que el argumento que apela a los sentimientos mayoritarios de los colombianos debe ser tomado con mucho cuidado pues estas encuestas imaginarias $o$, incluso, encuestas basadas en estudios empíricos reales no pueden convertirse en criterios definitorios para los procesos de constitucionalidad, ya que esto sería un gran riesgo para los grupos minoritarios ${ }^{42}$.

Por esto, la discusión constitucional debe partir de la base según la cual el Estado colombiano es un Estado laico con la libertad religiosa y de conciencia de las personas como principio fundamental. En virtud de esto, las actuaciones y decisiones de las autoridades públicas deben ser inclusivas, "comprensivas de esa diversidad, libertad y pluralidad y orientadas a la realización de los fines señalados en la Carta”. En otras palabras, para la Procuraduría, los valores religiosos de la mayoría de los colombianos, aunque válidos e importantes, son valores exógenos a la Constitución Política.

El Ministerio Público identifica un punto clave en el debate acerca del aborto, a saber, los aspectos metafísicos ineludibles del mismo en torno al "misterio del comienzo de la vida humana". Por esto, diferentes sociedades, en diferentes espacios y tiempos, han tenido diversas posiciones sobre el aborto. Para la Procuraduría,

42 En todo caso, la Procuraduría cita una encuesta realizada a un grupo de personas pertenecientes a la religión católica que evidencia que aunque la mayoría rechaza la interrupción voluntaria del embarazo también considera que la ley penal no debería inmiscuirse en estos asuntos por ser del resorte de la autonomía de la mujer. El 73\% de los católicos encuestados acepta el aborto cuando la vida de la mujer está en peligro; el $65 \%$ cuando la mujer tiene VIH/sida; el $66 \%$ cuando la salud de la mujer está en riesgo; el $61 \%$ cuando el feto tiene graves defectos físicos o mentales; y el 52\% cuando el embarazo es resultado de una violación. 
las valoraciones filosóficas, religiosas, sociales, demográficas o científicas de las que se parta permitirán justificar prohibiciones parciales o totales del aborto. Sin embargo, en las sociedades contemporáneas, a partir de la instauración del Estado Social y Democrático de Derecho, aparece un nuevo elemento que antes no se tenía en cuenta, a saber: los derechos fundamentales de la mujer. Esta última, según el Ministerio Público, es "la verdadera protagonista de esta circunstancia".

Ahora bien, en estricto sentido, las únicas intervenciones que tienen el carácter de participación ciudadana y que se pronuncian a favor de los cargos contra la norma para impugnar su inconstitucionalidad y en las que se citan argumentos con contenido referido a asuntos religiosos son las suscritas por las ciudadanas MARÍA Ximena Castilla-Jiménez y Sandra Patricia Mazo-Cardona.

Esta última, como representante legal en Colombia de la Corporación Católicas por el Derecho a Decidir, interviene para señalar que "sancionar penalmente el aborto implica la vulneración de derechos fundamentales y constituye un problema de salud pública, que debe ser atacado mediante la implementación de políticas públicas que beneficien a la población en general".

La intervención de la representante legal de Católicas por el Derecho a Decidir resulta interesante en la medida en que se identifica como miembro de un grupo con ideología claramente religiosa pero que defiende una posición que, si bien puede no ser representativa de la mayoría de ciudadanos católicos, refleja la pluralidad de pensamiento que existe entre los mismos ciudadanos creyentes. El ejercicio de participación que se realiza en esta intervención le impone a los ciudadanos religiosos una de las exigencias que propone HABERMAS para los ciudadanos religiosos: aceptar la existencia y validez de otras religiones y también la de otras líneas de pensamiento incluso en una misma religión.

\section{B. Intervenciones y conceptos en defensa de la norma que sanciona penalmente la IVE}

a. La intervención de la Conferencia Episcopal Colombiana, CEC, suscrita por el arzobispo de Tunja, solicita a la Corte declarar la exequibilidad de los artículos demandados. Técnicamente, la Con- 
ferencia Episcopal no es experta en el tema objeto de debate. En ese sentido, se podría pensar que esta argumentación constituye una intervención ciudadana del arzobispo de Tunja, que se identifica como ciudadano religioso al enunciarse como miembro de esa institución.

El arzobispo presenta argumentos jurídicos y seculares, como el reconocimiento al derecho a la vida que la Constitución Política realiza en el Preámbulo y en otras normas constitucionales y en la Convención Americana sobre Derechos Humanos, que reconoce explícitamente el derecho a la vida del no nacido ${ }^{43}$. Igualmente, se refiere a los precedentes constitucionales ${ }^{44}$, en los que se consideró que la vida humana debería ser protegida desde el momento de la concepción.

Hasta aquí, parece que la intervención de la Conferencia Episcopal Colombiana suscrita por el arzobispo, como ciudadano religioso, se esfuerza por traducir y exponer en un lenguaje secular convicciones religiosas. Se "traduce" el valor de la vida que el interviniente quiere defender a partir de los documentos jurídicos citados, participando como si se tratara de una esfera formal institucional. Sin embargo, en el resto de su intervención, se evidencian los límites a este ejercicio de traducción, pues son muchas las ideas religiosas que simplemente no pueden ser traducidas por entero en un lenguaje secular. Esto, en todo caso, es posible, e incluso deseable, una vez se acepta que las intervenciones ciudadanas en los procesos constitucionales se desarrollan en una esfera informal.

En su escrito, el arzobispo señaló que la tradición doctrinal de la Iglesia Católica ha sostenido siempre que la vida humana se deberá proteger y favorecer desde su comienzo. Para la Iglesia, según el arzobispo, la gravedad moral del aborto se explica porque en realidad se trata de un homicidio cualificado en el que la responsabilidad se deriva tanto de la madre como de todas las personas que intervienen.

43 Organización de Estados Americanos, OEA, Convención Americana sobre Derechos Humanos, Pacto de San José, San José, Costa Rica, 7-22 de noviembre de 1969, artículo 4. Disponible en: https://www.oas.org/dil/esp/tratados_B-32_Convencion_Americana_sobre_ Derechos_Humanos.htm

44 Corte Constitucional, Sentencia C-133-94, 17 de marzo de 1994, magistrado ponente Antonio Barrera-Carbonell. Disponible en: http://www.corteconstitucional.gov.co/ relatoria/1994/c-133-94.htm 
El arzobispo señala que la libertad no puede concebirse simplemente como un asunto personal y subjetivo en el cual la persona individual es la referencia única e indiscutible de sus decisiones. Al contrario, la idea de libertad, basada en una verdad objetiva y común, es el fundamento de la vida personal y social. Si se prescinde de lo anterior, en vez de decisiones libres y autónomas, tenemos simplemente decisiones egoístas y caprichosas que niegan al otro, el cual será reducido a un enemigo con quien eventualmente tendremos intereses opuestos e irreconciliables. En este contexto, todo se vuelve negociable, incluso el primero de los derechos fundamentales, a saber, la vida humana. Por esto, según el arzobispo, la Iglesia Católica se opone tan férreamente al aborto y a la eutanasia.

b. Miembros de la Iglesia Cristiana Carismática Tabernáculo de la Fe señalan que el derecho a la vida se extiende al momento mismo de la concepción y que varios estudios muestran que las mujeres que han abortado sufren afecciones de orden físico, psicológico y familiar, por lo que la prohibición del aborto es otra forma de proteger a la mujer.

c. La Intervención de David Pérez, miembro de la Red Latinoamericana de Abogados Cristianos y de la red Advocates International recuerda los compromisos internacionales adquiridos por Colombia, como el Pacto de San José y que está científicamente probado que el ser humano existe desde el momento mismo de la concepción. Por eso, la protección a la vida se debe extender de forma absoluta y total al nasciturus.

d. Varios extranjeros con una clara afiliación religiosa participaron. Entre ellos: la intervención amicus curiae de John Keown, profesor de ética cristiana en Georgetown University, y amicus curiae de David Albert Jones Ba (Escuela de Teología, Filosofía e Historia de Saint Mary's College). Estos escritos fueron presentados por la ciudadana colombiana Ilva Myriam Hoyos. Estos argumentos se pueden comprender como conceptos de expertos en teología. La pregunta para este tipo de conceptos sería si la Corte - dado el carácter formal de los conceptos, cuya finalidad es orientar el debate en los temas propios del debate constitucional-debe incorporar conceptos de expertos en teología, pese a que no se resuelve un problema constitucional sobre ese objeto de estudio. En el presente caso, podría pensarse que si se ha invocado como cargo la violación 
de la libertad de conciencia y de cultos con el tipo penal del aborto valdría la pena que la Corte aceptara conceptos que dieran luces en ese sentido.

e. La intervención del ciudadano Jorge Arturo Enciso incluye un argumento explícitamente religioso. Según él, la vida humana le pertenece exclusivamente a Dios, quien es el único que tiene la facultad de disponer libremente de la vida humana. También propone que se deben realizar campañas educativas que "afiancen los valores del respeto irrestricto hacia la vida y la dignidad de la persona humana con fundamento en los criterios objetivos de la Ley Divina". De las expresiones incluidas en la intervención se puede deducir que este ciudadano religioso ha participado en el debate desde una perspectiva informal sin asumir la carga de traducir sus argumentos.

f. La intervención de Pedro Alfonso Sandoval-Gaitán señala que la tradición cristiana del pueblo colombiano evidencia que el legislador está obligado a consagrar delitos que protejan la vida humana desde el momento mismo de la concepción. Según él, está plenamente probado que la vida humana comienza desde la fecundación del óvulo femenino. Este ciudadano señala que la Constitución Política, interpretada a partir de la tradición cristiana del pueblo colombiano, genera obligaciones al legislador, y no los conceptos, sin fuerza vinculante, que emiten los comités de seguimiento de los tratados internacionales. 


\section{CONCLUSIONES}

Para HABERMAs, las discusiones públicas desarrolladas en la "esfera pública informal" constituyen un escenario en el que los ciudadanos religiosos pueden expresar y justificar sus convicciones en un lenguaje religioso si no encuentran traducciones seculares para ellas. Pese a esta apertura hacia la religión, HABERMAS mantiene la tradición liberal en la "esfera pública formal", esto es, en el mismo rango institucional del Congreso, los jueces, las cortes y en general, la administración. En estos campos, todo el lenguaje debería ser secular.

En este texto, nos interesaba analizar la naturaleza del espacio argumentativo constituido por las intervenciones ciudadanas y los conceptos técnicos presentados en los procesos de constitucionalidad. De la reglamentación de ambos se puede deducir que sus escasas exigencias las ubicarían en una esfera pública informal, en la que los ciudadanos religiosos pueden participar y los ciudadanos no religiosos - y los jueces constitucionales - , asumiendo una postura democrática, deben escucharlos, en la medida en que unos y otros hacen parte del Estado democrático constitucional.

Adicionalmente, la naturaleza de la actividad de los tribunales constitucionales, tal como HABERMAs la concibe en su modelo deliberativo de democracia, exige que el ámbito de las intervenciones se considere como un espacio informal que haga posible una deliberación amplia e incluyente. Hay pues razones jurídicas y filosóficas para afirmar y defender el carácter informal de las intervenciones ciudadanas en estos procesos. Esto demuestra que, a pesar de ser una zona ambigua, la teoría democrática de HABERMAs contiene suficientes elementos conceptuales para solventar tal ambigüedad.

Es una zona ambigua porque en el mismo espacio se presentan otro tipo de argumentaciones de otra naturaleza. En efecto, el tipo de discurso se hace más institucional cuando se trata de conceptos emitidos por expertos en el marco del debate constitucional, y en esa medida, por ejemplo, la Universidad que participa por medio de su representante lo haría en calidad de experta académica o científica. Por esa razón, su participación tendría mayores exigencias, lo cual no sucede en el caso de los ciudadanos intervinientes, que podrían 
participar como ciudadanos religiosos sin mayores exigencias frente al contenido del discurso.

Como se mostró, los juicios de inconstitucionalidad incluyen también la participación del procurador general de la Nación, que deberá rendir concepto sobre la constitucionalidad de la norma acusada dentro de los 30 días siguientes a la admisión de la demanda. Además, el magistrado sustanciador está facultado según el artículo 13 del Decreto 2067 de 1991 para "invitar a entidades públicas, a organizaciones privadas y a expertos en las materias relacionadas con el tema del proceso a presentar por escrito que será público, su concepto sobre puntos relevantes para la elaboración del proyecto de fallo". Así mismo, por mayoría de sus miembros, la Corte puede convocar a quienes rindieron concepto a participar en las audiencias públicas que se realicen en el marco de la discusión sobre la constitucionalidad de la norma.

Los conceptos también tienen una función orientadora; quienes participan responden a la invitación que hace el juez constitucional para que en su calidad de expertos ilustren al juez constitucional en elementos claves del tema objeto de debate. Este es el caso de los extranjeros y organizaciones o instituciones nacionales e internacionales que pueden participar en calidad de Amici curiae. La Corte ha suscrito acuerdos con instituciones universitarias para recibir apoyo científico y académico en temas sometidos a su estudio ${ }^{45}$. Desde esta perspectiva, el ámbito de los conceptos constituye una esfera formal pues los autores no son ciudadanos que actúan como intérpretes en una discusión política democrática con repercusiones jurídico-constitucionales, sino expertos cuyo conocimiento sobre el tema es pertinente para aclarar la discusión.

La relevancia de la función orientadora de las intervenciones y conceptos en el debate de constitucionalidad es coherente con el ideal democrático que valora la participación de los ciudadanos. La Corte ha señalado:

(...) el imperativo de provocar el debate de constitucionalidad, se explica, entre otras razones, por la necesidad de permitir el aporte de quienes han partici-

45 Es el caso de la sentencia C-721-99, en el que la Corte suscribió acuerdos con algunas universidades para apoyar su labor. Corte Constitucional, Sentencia C-721-99, 29 de septiembre de 1999, magistrado ponente Alejandro Martínez-Caballero. Disponible en: http://www. corteconstitucional.gov.co/relatoria/1999/c-721-99.htm 
pado en la producción de la norma, de quienes son sus destinatarios o pueden verse afectados por ella, de aquellos que tienen a su cargo su aplicación, y del Ministerio Público como representante de la sociedad ${ }^{46}$.

\section{Agregó la Corporación:}

...esa dimensión participativa del debate atiende también al propósito de conjurar el peligro de la trivialización del juicio de constitucionalidad, al permitir que se incorporen al proceso, y enriquezcan el debate, quienes viven la norma y son conscientes de sus perfiles eventualmente lesivos del orden constitucional, o, por el contrario, de la manera en que, no obstante una apariencia de inconstitucionalidad, la misma resulta compatible con la Carta, aspectos estos que en un momento dado podrían escapar al juez constitucional en un análisis realizado a partir de una insuficiente configuración del debate de constitucionalidad ${ }^{47}$.

Desde esta perspectiva, puede afirmarse que la Corte ha intentado configurar una idea de ciudadanía compuesta por personas que hacen parte de la comunidad de intérpretes de la Constitución en los términos en que señala la propuesta de HABERMAS. Sin embargo, la relevancia de las intervenciones está limitada por su propia reglamentación. Se trata, como se señaló anteriormente, de un espacio informal reglado. Se ha previsto un término de diez días para que los ciudadanos participen.

Pese a que las intervenciones se reconocen como un aporte fundamental en el proceso de inconstitucionalidad, este período es considerado muy corto, lo que constituye un impedimento para la amplia participación de la ciudadanía, en la medida en que es posible que los ciudadanos no se enteren de la existencia de la demanda con el aviso fijado por la Corte en Secretaría.

Por esta razón, es frecuente que no se presente ninguna intervención ciudadana en los procesos originados por acciones públicas de inconstitucionalidad. En ocasiones este déficit de participación ciudadana se trata de remediar pidien-

46 Corte Constitucional, Sentencia C-229-04, 8 de marzo de 2004, magistrado ponente Rodrigo Escobar-Gil, consideraciones y fundamentos, 2.3.2.2. Disponible en: http://www.corteconstitucional. gov.co/relatoria/2004/C-229-04.htm

47 Corte Constitucional, Sentencia C-229-04, 8 de marzo de 2004, magistrado ponente Rodrigo Escobar-Gil, consideraciones y fundamentos, 2.3.2.2. Disponible en: http://www.corteconstitucional. gov.co/relatoria/2004/C-229-04.htm 
do conceptos a personas que el magistrado a cargo del proceso considere que pueden tener información u opiniones relevantes para el tema en cuestión ${ }^{48}$.

Es importante recordar que la demanda de inconstitucionalidad en el caso analizado estuvo precedida de un proyecto de litigio estratégico denominado LAICIA (Litigio de Alto Impacto en Colombia por la Inconstitucionalidad del Aborto), liderado por la abogada Mónica Roa y la organización no gubernamental Women's Link Worldwide. Esa organización diseñó una estrategia de litigio que incluía la acción legal, la movilización social y la presencia en los medios de comunicación. En esa medida, el proyecto valoró el escenario de las intervenciones ciudadanas como un mecanismo "para que en el debate jurídico se tuvieran en cuenta los argumentos que desde distintas disciplinas y posiciones políticas servirían para defender la liberalización de la legislación penal sobre aborto, y después para que las organizaciones que trabajaban sobre derechos sexuales y reproductivos se sintieran vinculadas al proceso" El proyecto debió tener en cuenta las limitaciones de tiempo que impone el proceso de inconstitucionalidad a las intervenciones y promovió un proceso de divulgación y comunicación con organizaciones de todo tipo para promover su participación. El resultado final fue un importante y nutrido proceso de participación en el que intervinieron organizaciones y personas nacionales y extranjeras y en diferentes materias que podían aportar al debate. Por su parte, y en gran medida como una reacción a este activismo, quienes estaban en contra del proceso de liberalización de la interrupción voluntaria del embarazo también realizaron un proceso similar con base en sus propios intereses.

La Corte Constitucional ha insistido en que las intervenciones tienen el propósito de que los ciudadanos intervinientes "le brinden al juez constitucional elementos de juicio adicionales que le permitan adoptar una decisión" ${ }^{50}$. De esta manera, en una sentencia como la C-355-06 en la que se discutía la constitucionalidad de la

48 Isabel Jaramillo-Sierra \& Tatiana Alfonso-Sierra, Mujeres, cortes y medios: la reforma judicial del aborto, 101 (Universidad de los Andes, Siglo del Hombre Editores, Bogotá, 2008).

49 Isabel Jaramillo-Sierra \& Tatiana Alfonso-Sierra, Mujeres, cortes y medios: la reforma judicial del aborto, 101 (Universidad de los Andes, Siglo del Hombre Editores, Bogotá, 2008).

50 Corte Constitucional, Auto 243-01, 11 de julio de 2001, magistrado ponente Jaime CórdobaTriviño. Disponible en: http://www.corteconstitucional.gov.co/relatoria/Autos/2001/A243-01. htm 
penalización absoluta de la interrupción voluntaria del embarazo, la amplia participación ciudadana y de expertos mediante conceptos, se puede valorar como una evidencia de que el asunto objeto de debate constitucional era (e, incluso, es), en términos de RAwLS, una cuestión divisiva que toca con las esencias constitucionales de un Estado, como el lugar de las libertades y la protección a la vida; un asunto altamente controvertido en una sociedad dividida por sus diversas concepciones políticas, filosóficas, religiosas y morales. Por esto es tan necesario aceptar la existencia de espacios multidimensionales formales e informales a la vez, como el espacio de las intervenciones ciudadanas y conceptos técnicos de expertos.

En el escenario de la participación en los procesos de inconstitucionalidad, la distinción entre intervenciones y conceptos se puede analizar desde las nociones de esfera pública informal y esfera pública formal. El hecho de que las intervenciones ciudadanas puedan leerse desde la esfera pública informal constituye una garantía para la participación de todos los ciudadanos en un debate público, de tal modo que puedan vincularse como ojos críticos de un espacio público-político jurídico politizado en el que son una parte importante de la comunidad de intérpretes de la Constitución.

Estas intervenciones le permiten al juez constitucional observar que el asunto objeto de debate no es un tema en que haya un acuerdo generalizado a favor o en contra de una tesis, lo que a su vez orienta al juez acerca del tipo de argumentación que debe asumir, una argumentación que logre persuadir a un auditorio variado y complejo. Por esta razón, no sería aceptable que la Corte Constitucional adoptara una perspectiva secularista - como en efecto no ocurrió en esta sentencia-, pues al tema se le dio una respuesta que buscara dar en el "justo medio"; es decir, ni liberalización absoluta ni prohibición absoluta ${ }^{51}$.

En todo caso, también sería deseable que el juez constitucional tuviera la capacidad y la disposición de incorporar en las intervenciones ciudadanas - esto es, en el auditorio explícito de ciudadanos intérpretes de la constitución - las voces de esos "públicos débi-

51 En este artículo no se analizan los argumentos mediante los cuales la Corte Constitucional tomó su decisión, la cual, como se recordará, consistió en despenalizar la interrupción voluntaria del embarazo en tres casos: embarazos producto de violación, incesto o inseminación artificial no consentida, cuando haya malformaciones del feto incompatibles con la vida y por razones terapéuticas, para proteger la vida y salud de la mujer gestante. 
les" que muchas veces suelen representar voces minoritarias con interpretaciones alternativas. Como lo señalamos anteriormente, hay muchas voces religiosas heterodoxas que, sin embargo, son oprimidas por las interpretaciones dominantes. Si se trata de admitir argumentos religiosos en la esfera pública informal, incluso en ámbitos relativamente mixtos como el espacio de las intervenciones ciudadanas y los conceptos técnicos en los procesos de constitucionalidad, es fundamental que los ciudadanos religiosos y seculares, y también los jueces constitucionales, estén conscientes de la pluralidad presente en los discursos religiosos mismos. 


\section{BIBLIOGRAFíA}

\section{Libros}

Estrada, Juan Antonio, Por una ética sin teología. Habermas como filósofo de la religión (Trotta, Madrid, 2004).

Habermas, Jürgen, Facticidad y validez: sobre el derecho y el estado democrático de derecho en términos de teoría del discurso (Trotta, Madrid, 1998).

Habermas, Jürgen, Entre naturalismo y religión (Paidós, Madrid, 2006).

Habermas, Jürgen, ;Ay, Europa! Pequeños escritos políticos (Trotta, Madrid, 2009).

Hoyos-Vásquez, Guillermo \& Rueda-Barrera, Eduardo A., eds., Filosofía política: entre la religión y la democracia (Editorial Pontificia Universidad Javeriana, Bogotá, 2011).

Jaramillo-Sierra, Isabel \& Alfonso-Sierra, Tatiana, Mujeres, cortes y medios: la reforma judicial del aborto (Universidad de los Andes, Siglo del Hombre Editores, Bogotá, 2008).

Rawls, John, Liberalismo político (Fondo de Cultura Económica, México, 1996).

\section{Colaboración en obras colectivas}

Lemaitre-Ripoll, Julieta, Anti-clericales de nuevo: La Iglesia Católica como un actor político ilegítimo en materia de sexualidad y reproducción en América Latina, en Derecho y Sexualidades, 286-304 (Marcelo Alegre, Karina Ansolabehere, Antonio Bascuñán-Rodríguez, Bo Burt, Jaime Couso, Ana Maria de OliveiraNusdeo, Carlos Alberto de Salles, Mónica González-Contró, lucas S. Grosman, Isabel C. Jaramillo, Julieta Lemaitre-Ripoll, Alejandro Madrazo, Fernando Muñoz L., Catalina Pérez-Correa, lourdes Peroni, Francisca Pou-Giménez, Mario Ramos-Reyes, Laura Saldivia, Reva B. Siegel, Esther Vicente \& Kenji Yoshin, Libraria, Buenos Aires, 2009). Disponible en: https:// www.academia.edu/3862378/LEMAITRE_RIPOLL_J._Anticlericales_de_ nuevo_la_Iglesia_Cat $\% \mathrm{C} 3 \% \mathrm{~B} 31$ ica_como_un_actor_ileg\%C3\%ADtimo_ en_sexualidad_y_reproducci\%C3\%B3n_en_Am $\% \mathrm{C} 3 \% \mathrm{~A} 9 \mathrm{rica}$ Latina_en Derecho_y_Sexualidades_ed._Lourdes_Peroni._Libraria_Buenos_Aires_2010

\section{Revistas}

Aguirre, Javier, Habermas y la religión en la esfera pública, 61 Revista Ideas y Valores, 148, 59-78 (2012). Disponible en: http://www.redalyc.org/pdf/809/80924112004.pdf

Aguirre, Javier, Habermas' Account of the Role of Religion in the Public Sphere: a Response to Cristina Lafont's Critiques through an Illustrative Political Debate about Same Sex Marriage, 39 Philosophy and Social Criticism, 7, 637-673 (2013).

Baumeister, Andrea, The Use of "Public Reason" by Religious and Secular Citizens: Limitations of Habermas' Conception of the Role of Religion in the Public Realm, 
18 Constellations, 2, 222-243 (2011).

Bernstein, Richard, Naturalism, Secularism, and Religion: Habermas's Via Media, 17 Constellations, 1, 155-166 (2010).

Boettcher, James W., Habermas, Religion and the Ethics of Citizenship, 35 Philosophy \& Social Criticism, 1-2, 215-238 (2009).

Cerella, Antonio, Religion and the Political Form: Carl Schmitt's Genealogy of Politics as Critique of Jürgen Habermas' Post-Secular Discourse, 38 Review of International Studies, 5, 975-994 (2012).

Chambers, Simone, How Religion Speaks to the Agnostic: Habermas on the Persistent Value of Religion, 14 Constellations, 2, 210-223 (2007).

Cooke, Maeve, Salvaging and Secularizing the Semantic Contents of Religion: the Limitations of Habermas's Postmetaphysical Proposal, 60 International Journal of Philosophy of Religion, 1, 187-207 (2006).

Cooke, Maeve, A Secular State for a Postsecular Society? Postmetaphysical Political Theory and the Place of Religion, 14 Constellations, 2, 224-238 (2007).

Estrada, Juan Antonio, Razón, lenguaje y religion, 226 Proyección: Teología y mundo actual, 223-232 (2007).

Garzón-Vallejo, Iván, Los dilemas del carácter público de los argumentos filosóficos y religiosos en el liberalismo de John Rawls, 30 Praxis Filosófica, 39-63 (2010). Disponible en: http://www.redalyc.org/pdf/2090/209019322003.pdf

Garzón-Vallejo, Iván, Deliberación democrática y razones religiosas: objeciones y desafíos, 9 Revista Co-herencia, 16, 81-117 (2012). Disponible en: http:// publicaciones.eafit.edu.co/index.php/co-herencia/article/view/1181/1068

Lafont, Cristina, Religion in the Public Sphere: Remarks on Habermas' Conception of Public Deliberation in Post-secular Societies, 14 Constellations, 2, 239-259 (2007).

Lafont, Cristina, Religion in the Public Sphere, 35 Philosophy \& Social Criticism, 1-2, 127-150 (2009).

Mejía-Quintana, Óscar, El dilema histórico de la decisión judicial: la teoría del derecho de Jürgen Habermas, 14 Revista Panameña de Política, 67-103 (2012). Disponible en: http://cidempanama.org/wp-content/uploads/2013/05/EL-dilemahist $\%$ C3\%B3ricoRPP14.pdf

Rawls, John, The Idea of Public Reason Revisited, 64 The University of Chicago Law Review, 3, 765-807 (1997). Disponible en: http://www.hartsem.edu/academic/ courses/summer2009/Idea $\% 20$ of $\% 20$ Public $\% 20$ Reason $\% 20$ Revisted $\% 20$ (Rawls). pdf

Singh, AaKash, Habermas' Wrapped Reichstag: Limits and Exclusions in the Discourse of Post-Secularism, 20 European Review, 1, 131-147 (2012).

Walhof, Darren R., Habermas, Same-Sex Marriage and the Problem of Religion in the Public Life, 39 Philosophy \& Social Criticism, 3, 225-242 (2013). 


\section{Tratados internacionales}

Organización de Estados Americanos, OEA, Convención Americana sobre Derechos Humanos, Pacto de San José, San José, Costa Rica, 7-22 de noviembre de 1969. Disponible en: https://www.oas.org/dil/esp/tratados_B-32_Convencion_ Americana_sobre_Derechos_Humanos.htm

\section{Normatividad colombiana}

Colombia, Constitución Política, expedida el 1 de diciembre de 1885, proclamada el 5 de agosto de 1886. Disponible en: http://www.alcaldiabogota.gov.co/sisjur/ normas/Norma1.jsp?i=7153

Colombia, Constitución Política, 4 de julio de 1991, 116 Gaceta Constitucional, segunda edición corregida, 20 de julio de 1991. Disponible en: http://www. secretariasenado.gov.co/senado/basedoc/constitucion_politica_1991.html

Colombia, Decreto 2067 de 1991, por el cual se dicta el régimen procedimental de los juicios y actuaciones que deban surtirse ante la Corte Constitucional, 40.012 Diario Oficial, 4 de septiembre de 1991. Disponible en: http://www. secretariasenado.gov.co/senado/basedoc/decreto_2067_1991.html

Colombia, Ley 19 de 1890, por la cual se expide el Código Penal, 18 de octubre de 1890. Disponible en: http://www.bdigital.unal.edu.co/6944/103/ley_19_de_1890_ codigo_penal_libro_primero.pdf

Colombia, Ley 95 de 1936, por la cual se expide el Código Penal, 24 de abril de 1936, 23.316 Diario Oficial, 24 de octubre de 1936. Disponible en: http://www.suinjuriscol.gov.co/viewDocument.asp?id=1791348

\section{Jurisprudencia colombiana}

Corte Constitucional, Auto 035-97, 2 de octubre de 1997, magistrado ponente Carlos Gaviria-Díaz. Disponible en: http://www.corteconstitucional.gov.co/relatoria/ autos/1997/A035-97.htm

Corte Constitucional, Auto 035-98, 15 de julio de 1998, magistrado ponente José Gregorio Hernández-Galindo. Disponible en: http://www.corteconstitucional.gov.co/ relatoria/Autos/1998/A035-98.htm

Corte Constitucional, Auto 243-01, 11 de julio de 2001, magistrado ponente Jaime Córdoba-Triviño. Disponible en: http://www.corteconstitucional.gov.co/ relatoria/Autos/2001/A243-01.htm

Corte Constitucional, Auto 251-01, 17 de julio de 2001, magistrado ponente Jaime Córdoba-Triviño. Disponible en: http://www.corteconstitucional.gov.co/ relatoria/Autos/2001/A251-01.htm

Corte Constitucional, Auto 054-04, 4 de mayo de 2004, magistrado ponente Eduardo Montealegre-Lynett. Disponible en: http://www.corteconstitucional.gov.co/ relatoria/Autos/2004/A054-04.htm 
Corte Constitucional, Auto 360-06, 6 de diciembre de 2006, magistrado ponente Clara Inés Vargas-Hernández. Disponible en: http://www.corteconstitucional.gov.co/ relatoria/Autos/2006/A360-06.htm

Corte Constitucional, Auto 257-09, 4 de agosto de 2009, magistrado ponente Gabriel Eduardo Mendoza-Martelo. Disponible en: http://www.corteconstitucional.gov. co/RELATORIA/Autos/2009/A257-09.htm

Corte Constitucional, Sentencia C-133-94, 17 de marzo de 1994, magistrado ponente Antonio Barrera-Carbonell. Disponible en: http://www.corteconstitucional.gov. co/relatoria/1994/c-133-94.htm

Corte Constitucional, Sentencia C-013-97, 23 de enero de 1997, magistrado ponente José Gregorio Hernández-Galindo. Disponible en: http://www.corteconstitucional. gov.co/RELATORIA/1997/c-013-97.htm

Corte Constitucional, Sentencia C-239-97, 20 de mayo de 1997, magistrado ponente Carlos Gaviria-Díaz. Disponible en: http://www.corteconstitucional.gov.co/ relatoria/1997/c-239-97.htm

Corte Constitucional, Sentencia C-536-98, 1 de octubre de 1998, magistrado ponente José Gregorio Hernández-Galindo. Disponible en: http://www.corteconstitucional. gov.co/RELATORIA/1998/C-536-98.htm

Corte Constitucional, Sentencia C-721-99, 29 de septiembre de 1999, magistrado ponente Alejandro Martínez-Caballero. Disponible en: http://www.corteconstitucional. gov.co/relatoria/1999/c-721-99.htm

Corte Constitucional de Colombia, Sentencia C-915-01, 29 de agosto de 2011, magistrado ponente Eduardo Montealegre-Lynett. Disponible en: http://www. corteconstitucional.gov.co/relatoria/2001/C-915-01.htm

Corte Constitucional, Sentencia C-229-04, 8 de marzo de 2004, magistrado ponente Rodrigo Escobar-Gil. Disponible en: http://www.corteconstitucional.gov.co/ relatoria/2004/C-229-04.htm

Corte Constitucional, Sentencia C-1155-05, 15 de noviembre de 2005, magistrado ponente Rodrigo Escobar-Gil. Disponible en: http://www.corteconstitucional.gov.co/ relatoria/2005/C-1155-05.htm

Corte Constitucional, Sentencia C-1187-05, 22 de noviembre de 2005, magistrado ponente Humberto Antonio Sierra-Porto. Disponible en: http://www.corteconstitucional. gov.co/relatoria/2005/C-1187-05.htm

Corte Constitucional, Sentencia C-355-06, 10 de mayo de 2006, magistrados ponentes Jaime Araújo-Rentería \& Clara Inés Vargas-Hernández. Disponible en: http:// www.corteconstitucional.gov.co/relatoria/2006/C-355-06.htm

Corte Constitucional, Sentencia C-194-13, 10 de abril del 2013, magistrado ponente Luis Ernesto Vargas-Silva. Disponible en: http://www.corteconstitucional.gov. co/RELATORIA/2013/C-194-13.htm 
